
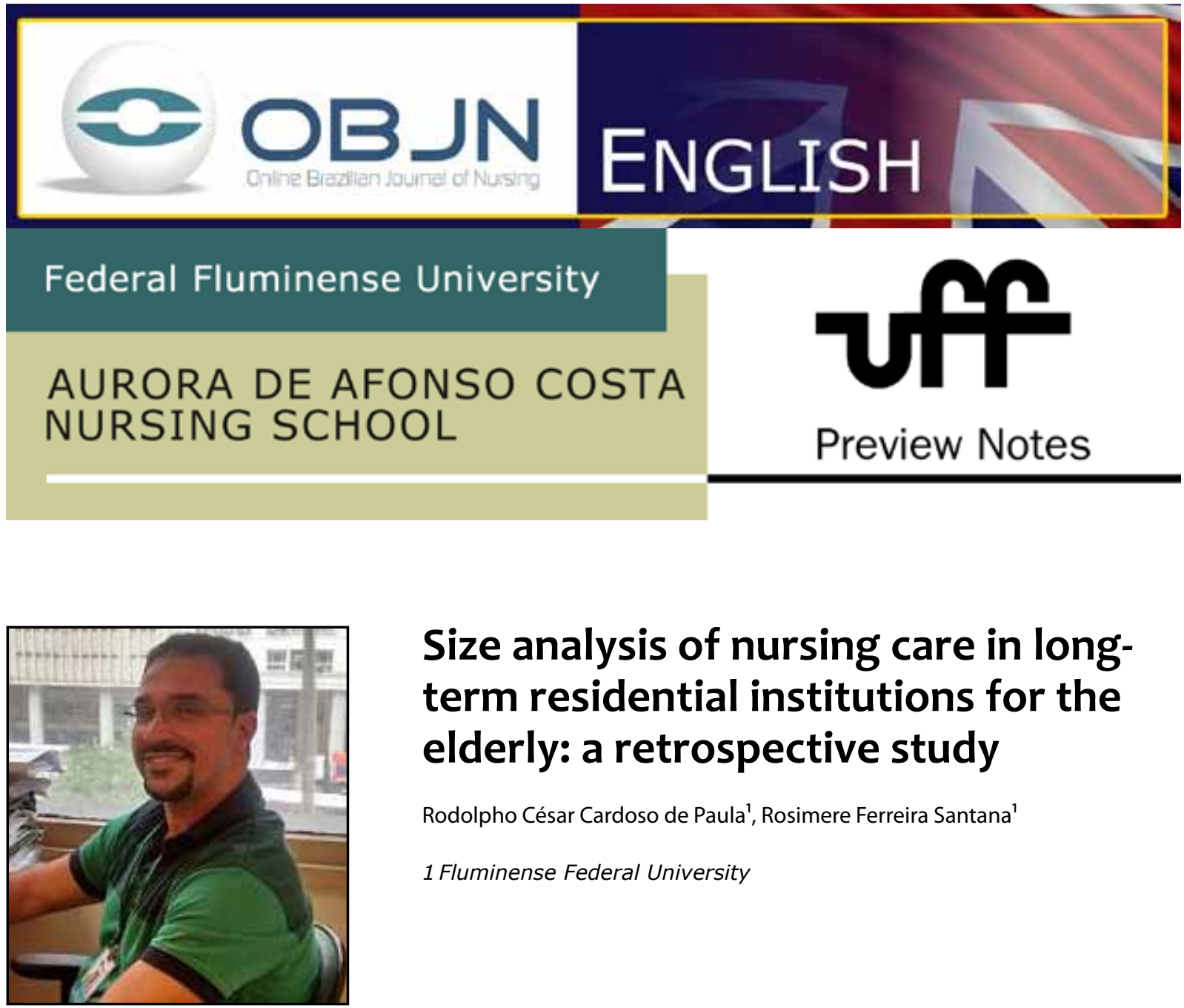

\title{
Size analysis of nursing care in long- term residential institutions for the elderly: a retrospective study
}

\author{
Rodolpho César Cardoso de Paula', Rosimere Ferreira Santana ${ }^{1}$ \\ 1 Fluminense Federal University
}

\begin{abstract}
Aim: To analyze the number of nursing personnel in long-term residential institutions for the eldely (RLTI), according to reports produced with regard to the ethical-professional supervision by the Regional Nursing Council. Method: This is a retrospective study, involving documentary analysis and a quantitative approach. Among the 1,895 trials generated from January 2010 to December 2013, there were 159 supervision trials in institutions of this kind. These will compose the initial sample used in this research. The instrument used to collect data will contain information related to the institution, the number of nursing personnel, and the classification of the elderly residing in these institutions. Results: We expect to generate a calculation of the original number of nursing professionals in institutions for the elderly. Implications for health: To ensure an adequate number of nursing professionals to allow for safe and damage-free care.

Descriptors: Legislation, Nursing; Personnel Downsizing; Health Services for the Aged; Homes for the Aged; Geriatric Nursing; Nursing Staff.
\end{abstract}




\section{INTRODUCTION}

The size of nursing teams is based on a systematic process that relates to the quantitative and qualitative planning and evaluation of professionals. It is necessary to provide assistance according to the particularity of health services, guaranteeing the safety of care workers and those in their care ${ }^{(1)}$.

In long-term residential institutions for the elderly (RLTI), there are many doubts regarding the size of staff and the consequent care nurses provide, in contrast to the regulatory standards of professional nursing practices in Brazil.

First, these institutions are considered to provide social assistance, and do not subscribe to the Brazilian National Register of Health Institutions (SCNES, in Portuguese). Despite this, they are not excused from ethical-professional nursing supervision as relates to formal institutions.

In general, residential elderly present comorbidities. Dementia generated from Alzheimer's disease is one of the most common causes of hospitalization. When there are other health issues, it is notable that there is an increase in drug medication ${ }^{(2)}$. As a consequence, there is increased risk of falling, outbreaks of aggression and stress, incontinence, immobility and iatrogenic episodes. The elderly are in need of specialized nursing care. In addition, being in a collective environment, there is an increased risk of infections.

Another issue involves the presence of other professionals who are not trained but who work as nurses: the caregivers ${ }^{(3)}$. There is also a great deal of difficulty in classifying the elderly in these institutions in order to arrive at a precise calculation of the necessary number of nursing professionals.

These are routine situations seen in supervision of the elderly that are contrary to the legal precepts involved in the work of nursing professionals.
Therefore, it can be seen that there is a need to propose an new calculation of the number of nursing personnel needed to assist the elderly in RLTI, based on the legal requirements that regulate the nursing profession, and other laws related to elderly care.

\section{Guiding question}

Are there irregularities regarding the number of nursing personnel in some RLTI supervised by the Brazilian Regional Nursing Council?

\section{Hypothesis}

- $\mathrm{H}_{0}$-There are no irregularities in terms of the number of nursing personnel in supervised RLTIs.

- $\mathrm{H}_{1}$ - There are some irregularities in terms of the number of nursing personnel in supervised RTLIs.

\section{General aim}

To analyze the number of nursing personnel in RTLI according to reports produced with regard to ethical-professional supervision performed by the Brazilian Regional Nursing Council.

\section{Specific aims}

- To characterize the number of nursing personnel in RTLI, according to reports produced with regard to ethical-professional supervision performed by the Brazilian Regional Nursing Council.

- To identify the compliance to related laws regarding professional nursing practice and to the holistic care of the health of the elderly.

- To propose an original and viable calculation in terms of nursing care in RTLI, following le- 
gal requirements with regard to professional practice.

\section{METHOD}

This is a retrospective involving a documentary analysis and adopting a quantitative approach. To gather the information, the administrative processes related to supervised RTLIs, from January 2010 to December 2013, will be considered.

From the 1,895 processes to be examined, 159 of them were selected to be part of the initial sample. The criteria of exclusion will be reports that did not clearly state the clientele, the number of professionals providing care, and the role of the nursing professionals in the institution.

The location of the research will be the Department of Supervision of the Regional Nursing Council of Rio de Janeiro, Brazil (DEFIS/ COREN-RJ, in Portuguese), which works with supervised institutions and professionals - the end activity of all Brazilian Regional Nursing Councils, looking to guarantee the provision of a safe, high-quality, effective professional nursing practice to society as a whole.

The instrument used to collect data will have information regarding the institution (identified by codes), the number of personnel, and the classification of the elderly residents in each institution.

The data collected will be organized through the use of an MS Excel 2007 spreadsheet. Later, the data will be analyzed and presented in tables or charts, incorporating percentage and inferential distributions, based on the use of the Statistical Package for the Social Sciences software (SPSS), version 13.0.

We expect that this study will establish the number of hours needed to calculate the number of nursing professionals for the elderly living in RLTIs, in order to guarantee safe care and a damage free environment.

This present study is part of a research project entitled "Evaluation of results of ethical-professional nursing supervisions according to the standards, professional legal practice, systematization of nursing care, numbers of nursing personnel, and accompanying laws proposed by the Brazilian Federal Nursing Council Resolution \#374/2011 in terms of residence in long-stay institutions for the elderly: a retrospective study", approved by the head institution and by the local Committee of Ethics in Research, under protocol \#606.995 in Apr/04/2014.

\section{REFERENCES}

1. Fugulin FMT, Rossetti AC, Ricardo CM, Possari JF, Mello MC, Gaidzinski RR. Tempo de assistência de enfermagem em Unidade de Terapia Intensiva: avaliação dos parâmetros propostos pela Resolução COFEN n²93/04. Rev Latino-Am Enfermagem [Internet]. 2012 [cited 2014 Jul 2]; 20(2):325-32. Available from: http://www.scielo. br/scielo.php?pid=S010411692012000200015\& script $=$ sci_arttext\&tIng=pt

2. Terassi M, Rissardo L, Peixoto J, Salci M, Carreira L. Prevalence of drug use in institutionalized elderly: a descriptive study. Online Braz J Nurs [Internet]. 2012[cited 2014 Jul 2]; 11(1). Available from: http://www.objnursing.uff.br/index.php/ nursing/article/view/3516

3. Brasil. Presidência da República. Casa Civil. Subchefia para assuntos jurídicos. Lei $n .{ }^{\circ} 7.498$ de 25 de junho de 1986. Dispõe sobre a regulamentação do exercício da enfermagem e dá outras providências. Diário Oficial [da] República Federativa do Brasil 25 jun 1986; Seção 1. [cited $2014 \mathrm{Jul}$ 2]. Available from: http://www.planalto. gov.br/ccivil_03/leis/L7498.htm 
Project Information: Dissertation Project of the Professional Master Program in Assisting Nursing at UFF.

Tutor: Prof. Rosimere Ferreira Santana, PhD

Address for mailing: Rodolpho César Cardoso de Paula

Rua Cristiano Machado, 1101 - Jardim América - Rio de Janeiro, Brazil.

Email: rodolphodepaula@hotmail.com
All authors participated in the phases of this publication in one or more of the following steps, in According to the recommendations of the International Committee of Medical Journal Editors (ICMJE, 2013): (a) substantial involvement in the planning or preparation of the manuscript or in the collection, analysis or interpretation of data; (b) preparation of the manuscript or conducting critical revision of intellectual content; (c) approval of the versión submitted of this manuscript. All authors declare for the appropriate purposes that the responsibilities related to all aspects of the manuscript submitted to OBJN are yours. They ensure that issues related to the accuracy or integrity of any part of the article were properly investigated and resolved. Therefore, they exempt the OBJN of any participation whatsoever in any imbroglios concerning the content under consideration. All authors declare that they have no conflict of interest of financial or personal nature concerning this manuscript which may influence the writing and/or interpretation of the findings. This statement has been digitally signed by all authors as recommended by the ICMJE, whose model is available in http://www. objnursing.uff.br/normas/DUDE_eng_13-06-2013.pdf

Received: 07/11/2014

Revised: 08/04/2014

Approved: 08/04/2014 